\title{
The Use of Lithium in the Treatment of Thyrotoxicosis
}

\author{
R. Temple, M. Berman, J. Robbins, and J. Wolff \\ From the Clinical Endocrinology Branch and Mathematical Research Branch, \\ National Institute of Arthritis, Metabolism, and Digestive Diseases, National \\ Institutes of Health, Bethesda, Maryland 20014
}

A в S T R A C T Since lithium has been shown to inhibit release of iodine from the thyroid, we have investigated its therapeutic potential in thyrotoxicosis. Eight detailed ${ }^{131}$ I kinetic studies were performed on seven thyrotoxic women and data was analyzed using a computer program. Lithium at serum levels of about $1 \mathrm{mE} /$ liter decreased the loss of ${ }^{131} I$ from the thyroid, led to a fall in serum ${ }^{131}$ I levels and diminished urinary ${ }^{131} \mathrm{I}$ excretion. Computer simulation of the lithium effect required, in every case, that lithium inhibit hormonal and nonhormonal thyroid iodine release. In five cases a second lithium effect was required for a satisfactory fit of the model soluton with observed data: namely, an inhibition of hormone disappearance from serum.

Neither inhibition of release nor of hormone disappearance seemed to be affected by methimazole (release: $52 \%$ decrease without methimazole, $60 \%$ with methimazole; hormone disappearance: $-60 \%$ decrease in both). When $\mathrm{Li}^{+}$was discontinued, recovery of the iodine release rate and hormone disappearance rate over the observed time span was variable, ranging from no recovery to rates that exceeded pre- $\mathrm{Li}^{+}$values.

When $\mathrm{Li}^{+}$is used alone its effect on serum hormone levels is diminished due to continued accumulation of iodide by the thyroid. Thus, serum thyroxine-iodine levels fell $21-30 \%$ in $6-8$ days in patients who did not receive methimazole and $15-67 \%$ in the methimazoletreated subjects. For prolonged therapy, therefore, a thiocarbamide drug must be used in conjunction with $\mathrm{Li}^{+}$. The similarity of inhibition of iodine release from the thyroid produced by $\mathrm{Li}^{+}$and iodides is discussed.

This work was presented in part at the 63rd Annual Meeting of the American Society for Clinical Investigation, 2 May 1971, in Atlantic City, N. J. (1).

All correspondence should be addressed to Dr. J. Wolff at NIH.

Recciced for publication 29 March $19 \pi 2$ and in revised form 28 June 1972.

\section{INTRODUCTION}

Although lithium (1) salts have been used to treat manicdepressive psychoses since 1948 (2), it was only in 1967 that goiter was noted in some of these patients (3). Investigation of the mechanism of goitrogenesis suggested that lithium ion blocks the release of iodine from thyroid gland without significantly impairing other aspects of thyroid function. This was first proposed by Sedvall (4) who observed a prolonged thyroid ${ }^{131} \mathrm{I}$ half-life in a patient with normal ${ }^{131}$ I uptake. In rats chronically treated with lithium (5) the rate of release of thyroid ${ }^{131} \mathrm{I}$ was reduced by as much as $80 \%$ and this was accompanied by the gradual development of small goiters. Other parameters of iodine metabolism were not markedly affected or were stimulated.

Antithyroid agents which block organification of inorganic iodine produce clinical relief of hyperthyroidism only after thyroid iodine stores are depleted, and this depletion may take many weeks to occur $(6,7)$. The only therapeutic agents that inhibits release of thyroid hormone directly is inorganic iodine, but problems created by its use include interference with a number of diagnostic measurements of thyroid function, a significant incidence of poor response or even exacerbated thyrotoxicosis (8), and delay of ${ }^{131} \mathrm{I}$ therapy. We therefore investigated $\mathrm{Li}^{+}$as a potential therapeutic agent in patients in whom a prompt decrease in thyroid hormone levels is required (1). While these studies were in progress, Burrow, Burke, Himmelhoch, Spencer, and Hershman (9) reported that lithium administration slowed the loss of ${ }^{131} \mathrm{I}$ from the thyroid glands of two thyrotoxic patients.

\section{METHODS}

\section{Subjects}

Seven thyrotoxic patients were referred to us by Washington area physicians. (We thank Doctors Larry Anderson,

2746 The Journal of Clinical Investigation Volume 51 October 1972 
TABLE I

Clinical Data in Patients Studied ${ }^{*}$

\begin{tabular}{|c|c|c|c|c|c|c|c|c|}
\hline Subject & Age & $\begin{array}{l}\text { Duration of } \\
\text { illness }\end{array}$ & $\begin{array}{c}\text { Time off } \\
\text { thiocarbamide } \\
\text { therapy at } \\
\text { start of } \\
\text { study }\end{array}$ & $\begin{array}{l}\text { Estimated } \\
\text { gland } \\
\text { size }\end{array}$ & $\begin{array}{l}\text { Mean sleeping } \\
\text { pulse during } \\
\text { week before } \\
\text { lithium }\end{array}$ & $\begin{array}{l}\text { Prelithium } \\
\text { BMR }\end{array}$ & $\begin{array}{l}\text { Prelithium } \\
\text { peak }{ }^{131} \text { I } \\
\text { uptake }\end{array}$ & $\begin{array}{c}\text { Eye } \\
\text { disease }\end{array}$ \\
\hline & $y r$ & $y r$ & & $g$ & & $\%$ & $\%$ & \\
\hline Ba. J. & 27 & 0.67 & No $R x$ & 30 & 95 & +10 & 33 & - \\
\hline Br. J. & 17 & 2 & 27 days & 70 & 100 & +31 & 83 & - \\
\hline G. F.-1 & 40 & 1.5 & No $R \mathbf{x}$ & 80 & 84 & +74 & 82 & - \\
\hline A. T. & 32 & 5 & 13 days & 80 & 95 & +63 & 78 & + \\
\hline G. 1 . & 46 & 2 & $15 \mathrm{yr}$ & 60 & 106 & +10 & 48 & - \\
\hline D. B. & 18 & 2 & 13 days & 40 & 74 & +49 & 58 & \\
\hline H. B. & 39 & 1 & 6 days & 60 & 89 & +46 & 7.3 & - \\
\hline G. F.-2f & 40 & 2 & 56 days & 80 & - & - & 67 & - \\
\hline
\end{tabular}

${ }^{*}$ For all patients: $T_{4} I$ was elevated (except in Ba. J.), free $T_{4}$ was elevated (except in Ba. J.), anti-thyroglobulin antibodies were absent, cholesterol was normal or low, thyroxine-binding globulin was normal.

$\ddagger$ Patient G. F. was studied twice.

Alice Brigham, Mason Robertson, Jay Shapiro, and Aryangat Sukamara for these referrals.) With one exception (G. V. had a widened mediastinum of uncertain etiology) they were found to be free of other significant illness, and were felt to be able to tolerate the delay in beginning established antithyroid therapy that was required for the study. All patients were females with diffusely enlarged thyroids; their clinical features are summarized in Table I. Those subjects who had been treated with thiocarbamide drugs before the study had not yet had a satisfactory response. All antithyroid therapy was discontinued for at least 6 days before the onset of the study. One patient was studied twice.

\section{Procedures}

Prestudy evaluation. All patients received a general physical and laboratory examination, and their thyroid status was evaluated with measurements of serum thyroxine-iodine $\left(T_{4} I\right),{ }^{1}$ free thyroxine $\left(T_{4}\right)$, antithyroglobulin antibodies, thyroxine-binding globulin, cholesterol, and basal metabolic rate $(B M R)$. Triiodothyronine $\left(T_{3}\right)$ was measured by radioimmunoassay through the generosity of Dr. Reed Larson (University of Pittsburgh). The prestudy data are summarized in Table I. Because of the known antimania effects of lithium, a detailed psychiatric evaluation, with particular attention to mood parameters, was performed on several patients before and during lithium administration.

Study protocol. The study was initiated by the i.v. injection of $200-300 \mu \mathrm{Ci}$ of carrier-free $\mathrm{Na}^{131} \mathrm{I}$ (except for G. F.-2 who received oral $\left.\mathrm{Na}^{-131} \mathrm{I}\right)$. The ${ }^{131} \mathrm{I}$ content of the thyroid gland, serum, and urine was then measured frequently for the next 24-36 hr. After this period, measurements were made about once per day except for the period after lithium therapy was begun, when their frequency was again increased for $24-36 \mathrm{hr}$. Thyroid gland ${ }^{131} \mathrm{I}$ activity was determined with a shielded $2 \times 2$ inch $\mathrm{NaI}$ crystal at a distance of $18 \mathrm{~cm}$ from crystal to radiation source. All measurements were compared to standards prepared from a

${ }^{1}$ Abbreviations used in this paper: BMR, basal metabolic rate; MMI, methylmercaptoimidazole; $\mathrm{T}_{3}$, triiodothyronine ; $T_{4}$, thyroxine; $T_{4} I$, thyroxine iodine. portion of the sample used for injection. For thyroid gland counting, the standard was placed in a plexiglass phantom. Serum and urine samples were counted in a well-type scintillation counter, generally to a counting error of $3 \%$ or less. In several patients (H. B., A. T., D. B., G. F.-1 and G. F.-2) this counting error was reached for the entire study, while in the others, somewhat higher counting errors (5-8\%) had to be accepted after 15-20 days. As a rule, serum specimens were obtained at the same time each morning. After total serum ${ }^{131} \mathrm{I}$ was measured, each specimen was precipitated and washed two to three times with cold $10 \%$ trichloroacetic acid and the protein-bound ${ }^{131} \mathrm{I}$ was counted after dissolving the precipitate in $1 \mathrm{~N} \mathrm{NaOH}$. Urine was collected for 6,12 , or 24 -hr intervals, and a portion was counted. ${ }^{131} \mathrm{I}$ excretion is expressed as the amount that would have been excreted in $24 \mathrm{hr}$ if the 6 or $12 \mathrm{hr}$ rate had been maintained, and the value is plotted at the middle of the collection period. The creatinine content of 24-hr urine specimens was measured to monitor the completeness of collections.

Serum thyroxine iodine by column (10) and cholesterol were measured three times a week; BMR was measured twice a week, using a Sanborn model 10 "Metabulator"; free thyroxine (performed by BioScience Laboratories, Van Nuys, Calif. [11]) and thyroxine binding globulin (performed by BioScience) were measured weekly. The resting pulse was taken at least once per night. In four studies, methimazole (methylmercaptoimidazole) ( $30 \mathrm{mg}$ each $6 \mathrm{hr}$ ) was begun 1-5 days after ${ }^{131} \mathrm{I}$ administration and was continued until the study was completed.

For several days before the start of lithium administration, lactose placebos were given every $8 \mathrm{hr}$. When rapid changes in the kinetic curves had ceased, lithium carbonate was substituted for the lactose placebo without the patient's knowledge. Serum $\mathrm{Li}^{+}$levels were then measured daily by atomic absorption spectrometry. Generally, the initial dose of lithium carbonate was $600 \mathrm{mg}$, which yielded a serum level of about $0.5 \mathrm{mEq} /$ liter $8 \mathrm{hr}$ later. Subsequently, 900 $1500 \mathrm{mg}$ per day (given in three or four doses) was required to maintain serum lithium levels of $0.6-1.20 \mathrm{mEq} /$ liter. For most studies a stable $\mathrm{Li}^{+}$concentration of about $1 \mathrm{mEq} / \mathrm{liter}$ was sought. After the lithium period placebo 


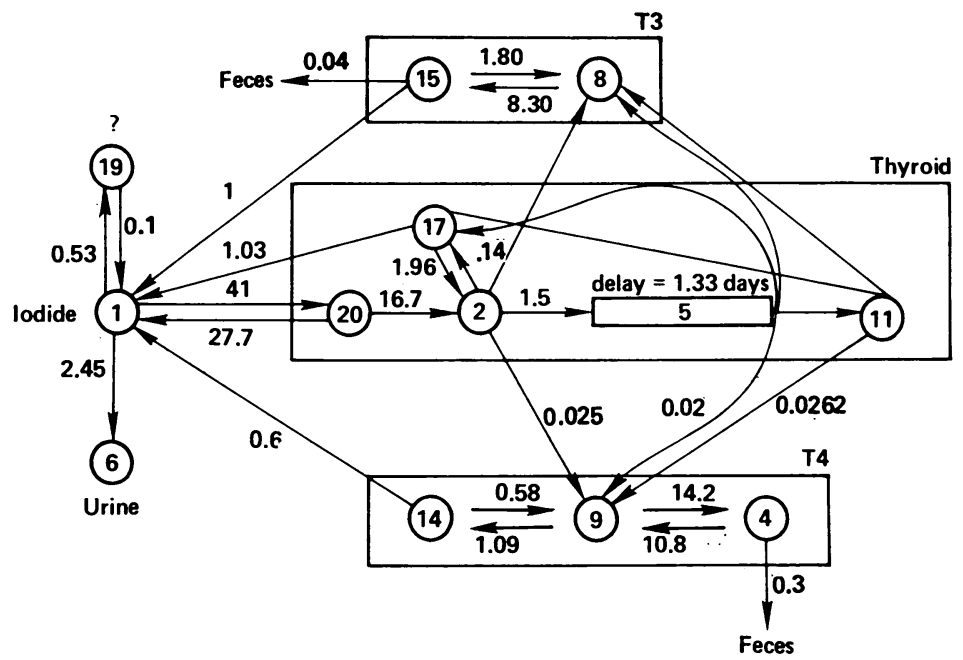

FIGURE 1 Modified ${ }^{131}$ I kinetic model used in the present analysis. The thyroid, $T_{3}$ and $T_{*}$ subsystems are depicted in rectangular boxes while individual compartments (comp.) are represented in circles. Rate parameters are those used for $\mathrm{Br}$. J. in the present study. In addition to the exposition of the model given previously (12-14) the following changes and assumptions should be noted: ( $a$ ) Three new compartments are introduced: 17, which represents intrathyroidal iodide recirculation; 20, which represents the iodide trap; and 19, which is a small, undefined pool of extrathyroidal, possibly organic iodine. It was necessary to introduce compartment 19 to satisfy the early iodide disappearance phases, especially from the point of view of conservation of administered activity. Its physiological significance, if any, is not clear. (b) Intrathyroid deiodination paths going to compartment 17 equal a constant times the sum of the paths from thyroid to extrathyroidal $T_{3}$ and $T_{4}$ (i.e., hormone secretion). In the non-MMI treated patients the magnitude of this constant could not be resolved and was set $=3.67$. (c) Thyroid measurement $=1 \times$ thyroid content $+0.05 \times$ comp $1+0.03 \times$ extrathyroidal $\mathrm{T}_{2}$ and $T_{*}$ (except for compartment 4 , which is considered to be liver $T_{4}$ ). $(d)$ Thyroid $\rightarrow \mathrm{T}_{3}$ paths are $\frac{1}{2}$ of thyroid $\rightarrow \mathrm{T}_{4}$ paths. There is considerable correlation between the $\mathrm{T}_{3}$ path and the iodide release path. (e) Early serum data are used in fitting to the model but are not shown in Figs. 2-5. ( $f$ ) $\mathrm{T}_{4}$ measurement $=$ comp 9/volume 9. $(g)$ Plasma equivalent spaces : comp $8=17.2 \%$ of body weight; comp $9=4.08 \%$ of body weight. ( $h$ ) Lithium effects. Thyroid: same factor applied to the following thyroid rate constants :

$$
\begin{array}{ccc}
\mathrm{L}_{9,2}, & \mathrm{~L}_{9,5}, & \mathrm{~L}_{9,11} \\
\mathrm{~L}_{8,2}, & \mathrm{~L}_{8,5}, & \mathrm{~L}_{8,11} \\
\mathrm{~L}_{17,2}, & \mathrm{~L}_{17,5} & \mathrm{~L}_{17,11},
\end{array}
$$

where $\mathrm{L}_{1, j}$ is rate constant into compartment $\mathrm{i}$ from $\mathrm{j}$ (units: day ${ }^{1-}$ ). Peripheral hormones: same factor applied to deiodination pathways: $\mathrm{L}_{1,14}$ and $\mathrm{L}_{1,15}$.

administration was resumed while kinetic and other studies continued for another 1-2 wk.

Analysis of data. The kinetic data were analyzed using a general model of iodine metabolism (Fig. 1) modified from Berman et al. (12-14) and the digital computer program SAAM/25, the latest of the SAAM series (15). Beginning with a set of initial estimates for the rate constants $L_{1, j}$ (designated $\lambda_{1, j}$ in previous papers $[12,14]$ ), the computer iteratively adjusted their values until a least squares fit of all the data for a particular study was obtained. Certain of the rate constants were allowed to change during the period of lithium administration and again during the period after lithium treatment. The general approach was to determine whether adjustment of a single parameter during lithium administration was sufficient for a satisfactory fit to the data, and whether failure to adjust that parameter would result in a poor fit even with all other parameters free to adjust (necessary condition). As will be seen, in some cases adjustment of a single parameter was sufficient, while in others, a second, extrathyroidal effect of $\mathrm{Li}^{+}$had to be introduced to account for the data. This second site of action would not have been detected without use of the model, and these results have suggested further studies. 
The model (Fig. 1) provides for secretion of hormonal and nonhormonal I from several compartments (12-14), but we did not find it necessary to introduce different lithium effects for each compartment (see legend to Fig. 1). The effect is therefore expressed by a single rate constant for total iodine secretion: the total fractional thyroidal iodine release rate, $L_{T}$.

For any compartment $i$, with content $M_{1}$, the secretion of iodine into compartment $\mathrm{j}$ is $\mathrm{M}_{1} \cdot \mathrm{L}_{\mathrm{j}, 1}$. Thus, total thyroxine secretion $\left(R_{T_{4}}\right)$ is :

$$
\mathrm{R}_{\mathrm{T}_{4}}=\mathrm{L}_{9,2} \mathrm{M}_{2}+\mathrm{L}_{9,5} \mathrm{M}_{5}+\mathrm{L}_{9,11} \mathrm{M}_{11} \text {. }
$$

Dividing by the total intrathyroidal iodine pool, $\mathbf{M}_{\mathbf{T}}$ (where $\mathrm{M}_{\mathrm{T}}=\mathrm{M}_{2}+\mathrm{M}_{5}+\mathrm{M}_{11}+\mathrm{M}_{17}+\mathrm{M}_{20}$ ), yields the fractional release rate of thyroxine, $\mathrm{L}_{\mathrm{T}_{4}}$ :

$$
\mathrm{L}_{\mathrm{T}_{4}}=\frac{\mathrm{R}_{\mathrm{T}_{4}}}{\mathrm{M}_{\mathrm{T}}} .
$$

Similarly, for triiodothyronine, the fractional release rate is:

$$
L_{T_{3}}=\frac{L_{8,2} M_{2}+L_{8,5} M_{5}+L_{8,11} M_{11}}{M_{T}} .
$$

The fractional release rate of iodide is similarly derived. Because iodine initially secreted as iodotyrosine is very quickly converted to iodide, iodotyrosine-iodine is treated as part of the iodide compartment:

$$
\mathrm{L}_{\mathrm{I}^{-}}=\frac{\mathrm{L}_{1,20} \mathrm{M}_{20}+\mathrm{L}_{1,17} \mathrm{M}_{17}}{\mathrm{M}_{\mathrm{T}}} .
$$

Finally, the total fractional thyroidal iodine release rate is $\mathrm{L}_{\mathrm{T}}=\mathrm{L}_{T_{4}}+\mathrm{L}_{\mathrm{T}_{3}}+\mathrm{L}_{\mathrm{I}^{-}}$. A detailed description of the revised model will be published elsewhere by M. Berman.

\section{RESULTS}

Patients with no organification block. Figs. 2 and 3 show kinetic data from two of the four patients who received lithium without methimazole; they illustrate features common to all of these patients as well as some of the variations observed in different studies. After lithium administration there was an abrupt decrease in the rate of loss of thyroidal radioactivity and the decrease persisted throughout the period of $\mathrm{Li}^{+}$treatment. However, the thyroid release curves showed marked variation upon cessation of lithium therapy. The rate of loss increased to nearly its prelithium rate in one case, changed little in two cases (e.g., Fig. 3) and increased, but not to its prelithium rate, in the fourth (Fig. 2).

Upon initiation of $\mathrm{Li}^{+}$treatment, serum and urine ${ }^{151} \mathrm{I}$ values fell from their pretreatment plateau values. These changes are consistent with, but do not prove, a decrease of ${ }^{131} \mathrm{I}$ release from the gland. In three of the four patients the urinary ${ }^{131} \mathrm{I}$ excretion fell more rapidly during the first $48-72 \mathrm{hr}$ of lithium treatment than did serum ${ }^{131}$ I levels; subsequently, the two values decreased at nearly comparable rates. The urinary ${ }^{131} \mathrm{I}$ derives from both peripheral breakdown of thyroid hormones and direct thyroidal secretion of iodide. The component arising

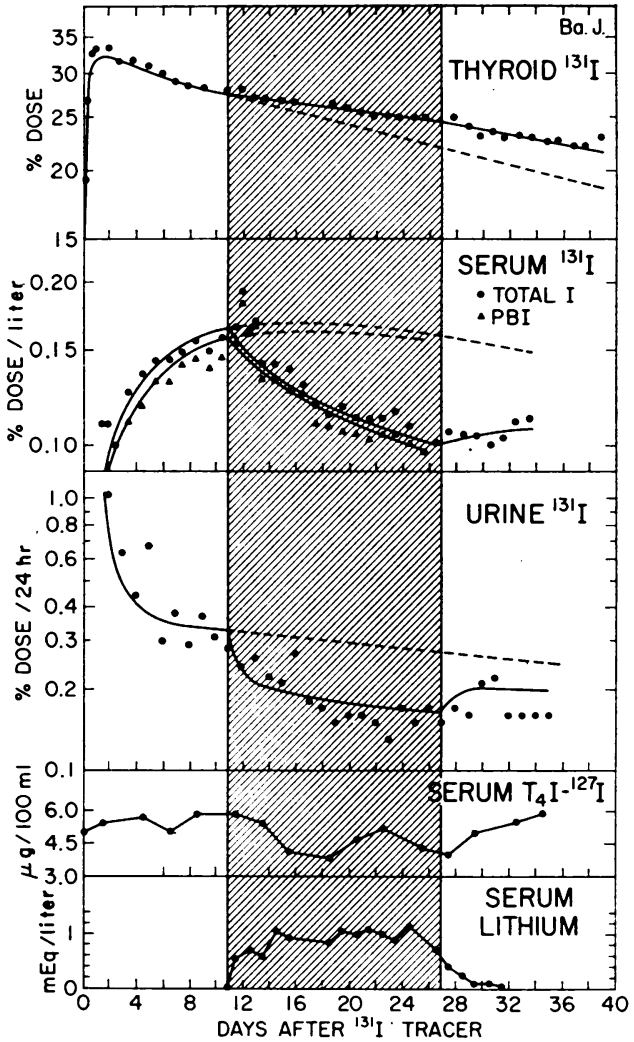

FIGURE $2{ }^{131} \mathrm{I}$ kinetics, serum $\mathrm{T}_{4} \mathrm{I}$ and serum $\mathrm{Li}^{+}$for patient $\mathrm{Ba}$. J. At time zero $\mathrm{Na}^{131} \mathrm{I}$ was given intravenously; the shaded area is the period of lithium administration. Solid circles and triangles represent measured data while solid lines in the three upper sections of the figure are the computer-generated least squares solutions, assuming that lithium affected only iodine release. The dashed line is the computer-generated description of the behavior of the curves if lithium had not been given.

directly from secretion would be expected to fall rapidly after any interference with secretion and the rapid early fall of urinary ${ }^{131} \mathrm{I}$ reflects this. Serum ${ }^{131} \mathrm{I}$ levels, representing mainly hormone iodine, decay slowly even after an abrupt decrease in secretion. The portion of urinary iodide derived from serum ${ }^{131} \mathrm{I}$ declines in parallel with it. In three of the four studies (the exception is $\mathrm{Br}$. J., Fig. 3) discontinuation of lithium treatment led to increased urinary ${ }^{151} \mathrm{I}$ excretion and serum ${ }^{151} \mathrm{I}$ levels.

The kinetic data were analyzed as described in Methods. The least squares fits are drawn in solid lines in the figures, whereas the dashed lines represent the behavior of ${ }^{131} \mathrm{I}$ that would have occurred without $\mathrm{Li}^{+}$therapy in these patients. For Ba. J. (Fig. 2), who was mildly thyrotoxic on the basis of nonsuppressible ${ }^{131} \mathrm{I}$ uptake and elevated $T_{3}$, the data could be fitted, with an acceptably small error (solid line, Fig. 2), by assuming that the only effect of lithium was on total ${ }^{131} I$ release $\left(L_{T}\right)$ from 

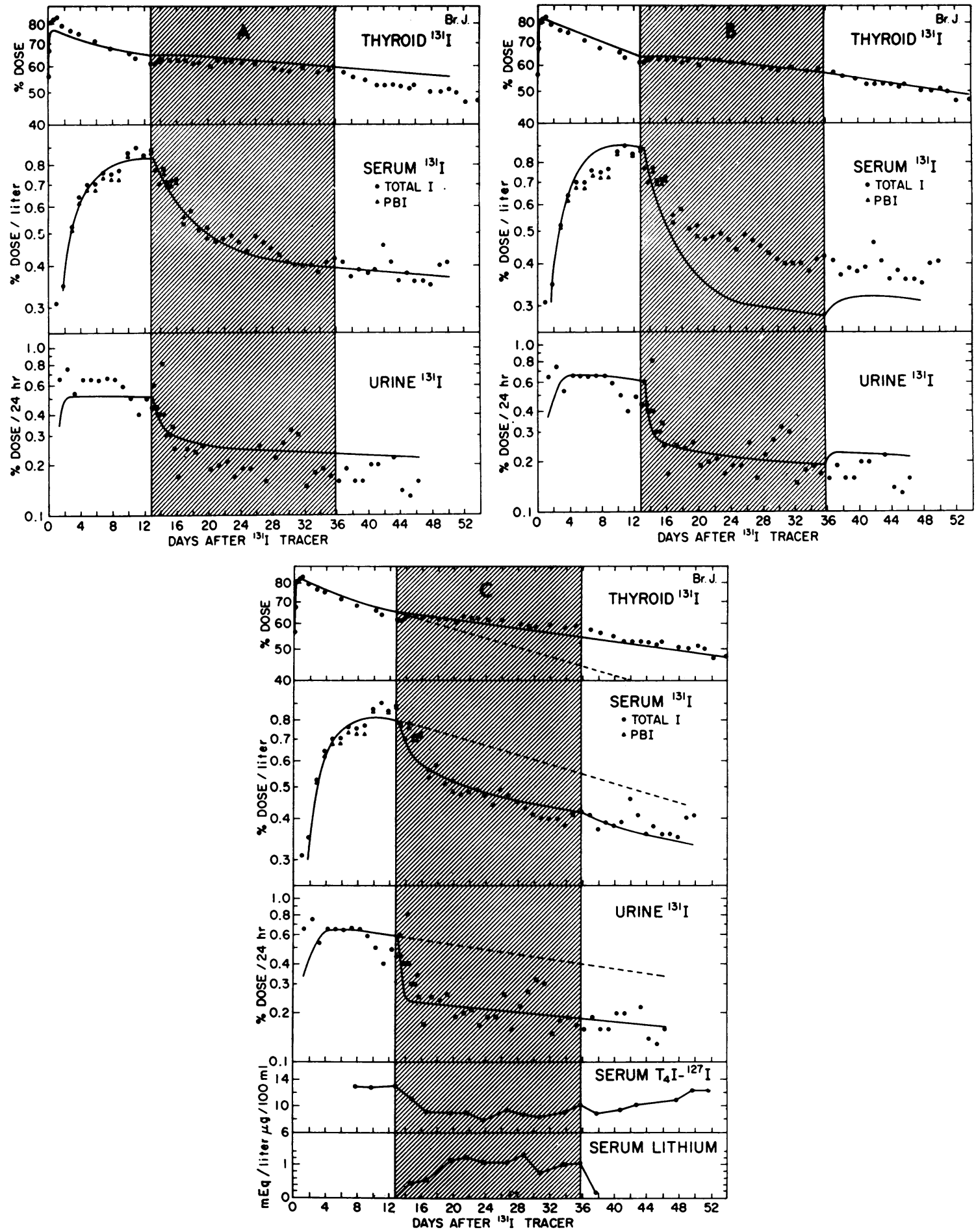

FIGURE 3 Comparison of computer solutions assuming different lithium effects, for patient $\mathrm{Br}$. J. $\mathrm{Na}^{-{ }^{131} \mathrm{I}}$ was given intravenously at time zero; the shaded area is the period of lithium administration. Solid circles and triangles represent measured data in $3 A, 3 B$, and $3 C$. Solid lines (the $\mathrm{PB}^{-131} \mathrm{I}$ line is omitted) are computer-generated least squares solutions generated under the following assumptions: $3 A$, lithium affected only iodine release; $3 B$, lithium affected only iodine release and no weight in the computer solution is to be given to serum data (that is, the curve is fitted only to thyroid and urine data) ; $3 C$, lithium affected both iodine release and hormone disappearance. The broken lines in $3 C$ are the description of the behavior of the curves if lithium had not been given. 
TABLE II

Fraction of Pretreatment Total ${ }^{131} I$ Release Rates $\left(L_{T}\right)$ and $T_{3}+T_{4}$ Deiodination Rate Attained during and after $\mathrm{Li}^{+}$Therapy

\begin{tabular}{|c|c|c|c|c|c|c|}
\hline \multirow[b]{3}{*}{ Patient } & \multirow[b]{3}{*}{$\begin{array}{c}\text { Methimazole } \\
\text { treatment }\end{array}$} & \multirow[b]{3}{*}{$\begin{array}{l}\text { Pretreatment } \\
\text { release rate }(\mathrm{L} T)\end{array}$} & \multicolumn{4}{|c|}{ Fraction of pretreatment rates* } \\
\hline & & & \multicolumn{2}{|c|}{ On lithium } & \multicolumn{2}{|c|}{ After lithium $\ddagger$} \\
\hline & & & Release & $\begin{array}{c}T_{3}+T_{4} \\
\text { deiodination }\end{array}$ & Release & $\begin{array}{c}T_{3}+T_{4} \\
\text { deiodination }\end{array}$ \\
\hline & & fraction/day & & & & \\
\hline Ba. J. & - & 0.026 & 0.52 & 0.85 & 0.70 & 0.85 \\
\hline Br. J. & - & 0.098 & 0.37 & 0.30 & 0.37 & 0.35 \\
\hline G. F.-1 & - & 0.137 & 0.33 & 0.25 & 0.60 & 0.30 \\
\hline A. $\mathrm{T}$. & - & 0.098 & 0.70 & 0.95 & 1.60 & 1.80 \\
\hline G. V. & + & 0.013 & 0.40 & 0.60 & 0.65 & 0.60 \\
\hline D. B. & + & 0.058 & 0.15 & 0.40 & 0.25 & 0.45 \\
\hline H. B. & + & 0.031 & 0.70 & 1.00 & $\S$ & \\
\hline G. F.-2 & + & 0.170 & 0.35 & 0.50 & 1.40 & 1.40 \\
\hline
\end{tabular}

* These values are calculated on the basis of 1.00 for the pretreatment values. They may be converted to per cent inhibition by (1.00-fraction) $\times 100$.

$\ddagger$ Recovery values are rough estimates. See text.

$\$$ A skin rash required discontinuation of methimazole shortly after lithium was stopped.

the gland, a decrease of $47 \%$. A slightly better fit could be obtained by assuming that lithium also caused a decrease in the fractional rate of disappearance of $T_{4}$ from the serum. The best fit in this case (Table II) corresponds to a $48 \%$ inhibition of thyroid ${ }^{151} \mathrm{I}$ release and a $15 \%$ decrease in fractional $T_{4}$ disappearance rate. Changes in parameter values of as little as $15 \%$ cannot be resolved definitely from these data so that either solution can be considered consistent with the observed kinetic curves. The kinetic parameters did not return to their original values when lithium was discontinued, the iodine release rate reaching only $70 \%$, and the $\mathrm{T}_{4}$ disappearance rate remaining $85 \%$ of the pretreatment rates. The effect of lithium therapy is strikingly shown by the dashed lines which simulate the ${ }^{131} \mathrm{I}$ kinetics that would have occurred in the absence of $\mathrm{Li}^{+}$therapy.

A more striking effect of $\mathrm{Li}^{+}$is seen in $\mathrm{Br}$. $\mathrm{J}$. who was severely thyrotoxic (Table I). The abrupt change in neck counts, the diminution of urinary ${ }^{131} \mathrm{I}$ excretion, and the fall of serum total and protein-bound ${ }^{131} \mathrm{I}$ are more impressive than in the study of $\mathrm{Ba}$. $\mathrm{J}$. In contrast to Ba. J. (Fig. 2), the data could not be fitted by assuming that lithium affected a single parameter (total ${ }^{181} \mathrm{I}$ release rate). If parameters were adjusted to fit the serum data (Fig. 3A) marked deviations between the model (solid lines) and the data occurred in both the urine and thyroid curves. When, on the other hand, they were adjusted to fit the thyroid data, a reasonable fit to the observed urine data could be obtained, but satisfactory matching of the serum kinetic curve could not be achieved (Fig. $3 B$ ). Since the fit of the data before $\mathrm{Li}^{+}$treatment was satisfactory, it seemed that the deviations in the serum curve resulted from the $\mathrm{Li}^{+}$therapy. The too rapidly falling serum curve suggested, furthermore, that if the serum ${ }^{131} \mathrm{I}$ disappearance were decreased a better fit might be obtained. Introduction of a factor to correct for the extent of the deviation in serum ${ }^{131} \mathrm{I}$ yielded much improved fits (Fig. $3 C$ ). Moreover, the post- $\mathrm{Li}^{+}$recovery showed an improved fit as well.

It is of considerable interest that while a $\mathrm{Li}^{+}$effect on release was anticipated from our rat studies (5) and would be consistent with the neck counts in these patients, an effect on $T_{4}$ disappearance from the serum was not expected from the rat data and was not observed in one case of thyrotoxicosis. ${ }^{2}$ For these reasons $T_{4}$ disappearance studies were not performed in our patients. The rigorous testing of the model, however, required this additional locus of lithium action. The effect on disappearance could be due to changes in one of the following: fecal excretion rate, thyroxine space, or degradation rate. Since the higher serum ${ }^{131} \mathrm{I}$ is accompanied by diminished loss of radioactivity in the urine (e.g., Fig. $3 A$ ), it seems reasonable to ascribe this second $\mathrm{Li}^{+}$effect to decreased deiodination. In our modeling, therefore, the lithium effect on $T_{\text {}}$ disappearance has been placed in the deiodination pathway $\left(L_{1,14}\right)$ and we have left the rate of fecal losses unaltered (Lreces, 4 ). This is not meant to suggest that the latter parameter could not be affected; only that we did not need to introduce any change to obtain the quality of fit shown.

${ }^{2}$ Dr. R. S. Bernstein, St. Louis, Mo. Personal communication. 


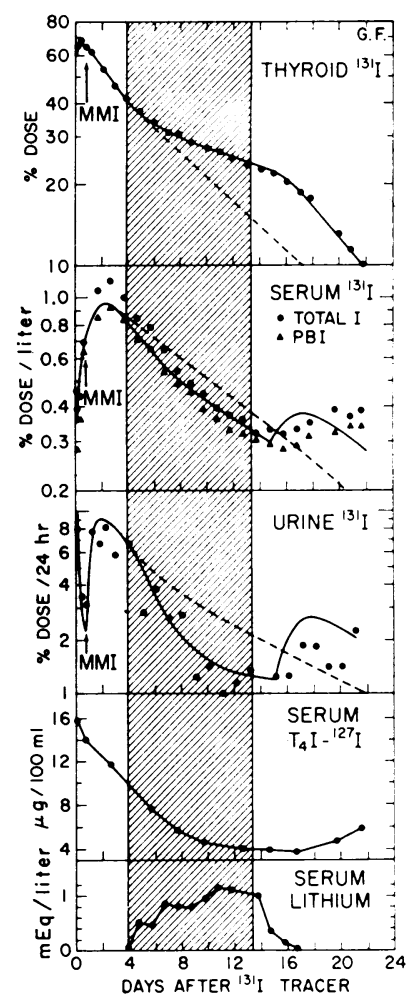

FIgURE $4{ }^{131} \mathrm{I}$ kinetics, serum $\mathrm{T}_{4} \mathrm{I}$, and serum $\mathrm{Li}^{+}$for patient G. F-2. At time zero $\mathrm{Na}^{-{ }^{131} \mathrm{I}}$ was administered orally; the shaded area is the period of lithium administration. Arrows mark the start of methimazole treatment at $30 \mathrm{mg}$ each $6 \mathrm{hr}$. Solid circles and triangles are data points; solid and dashed lines have the same meaning as in Fig. 2; the $\mathrm{PB}^{131} \mathrm{I}$ line is omitted.

It should be pointed out that even with this improved fit the model shows two areas of discrepancy with the data. Both of these occur during periods of changing $\mathrm{Li}^{+}$ concentration (i.e., onset and cessation of therapy). Although no attempt was made to develop a dose response curve for the lithium effect, changes in the rate of ${ }^{131} \mathrm{I}$ loss from the gland and in the rate of urinary ${ }^{131} \mathrm{I}$ excretion could be detected in all patients within $24 \mathrm{hr}$ after the first lithium dose. At that time the serum lithium was never more than $0.5 \mathrm{mEq} /$ liter, which can thus be taken as an upper limit for the minimum effective dose. However, a full $\mathrm{Li}^{+}$effect was probably not attained at this time and, since the model assumed an instantaneous $\mathrm{Li}^{+}$ effect, the early deviations may be due to this approximation.

The other two patients, A. T. and G. F.-1, who were treated with $\mathrm{Li}^{+}$alone, showed essentially similar responses in their iodine kinetics. In A. T. a relatively small effect was obtained (Table II) and changes in degradation rate were not acquired to obtain a good fit of the data to the model. The poor response may be due to the fact that $\mathrm{Li}^{+}$levels hovered around $0.6 \mathrm{mEq} /$ liter. The study of G. F.-1 gave results rather similar to those of Br. J., except that during the second week of lithium therapy there was a diminution of the lithium effect associated with a fall in serum lithium from about 1.0 $\mathrm{mEq} /$ liter to $0.6 \mathrm{mEq} /$ liter. Recovery of the kinetic parameters was variable. A. T. showed a return to normal of all ${ }^{131} \mathrm{I}$ parameters when the serum $\mathrm{Li}^{+}$had declined to $<0.1 \mathrm{mEq} /$ liter, whereas G. F.-1 showed an incomplete return to the pretreatment rate of loss of ${ }^{131} \mathrm{I}$ from the thyroid (Table II).

Patients with organification block. Since the slopes describing thyroid ${ }^{131} \mathrm{I}$ loss and urinary ${ }^{131} \mathrm{I}$ excretion are markedly damped by recirculation of radioisotope, four studies were performed in the presence of large doses of methimazole in order to reduce uptake parameters toward zero, and enhance the changes in slope due to lithium.

Two of these studies are presented in Figs. 4 and 5 . Methimazole therapy was associated in all cases with a prompt increase in the rate of thyroid ${ }^{131} \mathrm{I}$ loss, as was expected from the inhibition of recirculation of iodide. Lithium promptly diminished this rate of loss in all four patients. Although the onset of the $\mathrm{Li}^{+}$effect was prompt (Figs. 4 and 5), the rate decreased further after several days of treatment. In D. B. this may have been related to somewhat higher serum lithium levels. This behavior is like that seen in some of the patients not simultaneously treated with methimazole.

Serum ${ }^{131} \mathrm{I}$ levels were allowed to plateau before $\mathrm{Li}^{+}$ treatment was begun. In G. F.-2 the methimazole period was shortened because of severe thyrotoxicity. With lithium administration, serum ${ }^{131} \mathrm{I}$ began to decline and continued to do so, although at a decreasing rate. until the lithium was discontinued, at which time it either stabilized at about $40-50 \%$ of the prelithium values (Fig. 5) or rose slightly (Fig. 4 ).

Urinary ${ }^{131} \mathrm{I}$ excretion, which was dramatically increased by methimazole in all patients, fell very rapidly for $2-3$ days after the onset of lithium treatment, as it had in three of the four studies without methimazole. It then continued to fall roughly in parallel with the serum values until lithium treatment was stopped, at which time there was a slight, short-lived rise.

In this group of patients the inhibition of thyroid ${ }^{131} \mathrm{I}$ release produced by $\mathrm{Li}^{+}$treatment varied from $30-85 \%$ (Table II). In order to fit the observed data, it was again necessary to introduce a second effect of $\mathrm{Li}^{+}$on the iodine kinetics, namely an inhibition of peripheral hormone disappearance. In the cases of D. B. and G. F.-2 the serum ${ }^{131}$ I deiodination rate was reduced $60 \%$ and $50 \%$, respectively. In one of the two other patients of this group (H. B.) $\mathrm{Li}^{+}$had no effect on $\mathrm{T}_{4}$ disappearance, whereas in the fourth (G. V.) there was a re- 
duction in deiodination of $40 \%$ (Table II). The extent of the $\mathrm{Li}^{+}$effect upon the three kinetic curves is again indicated by the dashed lines which portray the behavior of the model that would occur in the absence of a $\mathrm{Li}^{+}$effect (Figs. 4 and 5).

A summary of the effects of $\mathrm{Li}^{+}$on those kinetic parameters which exhibit the major changes during treatment is given in Table II. It is apparent that there are wide variations in the response of both the total ${ }^{281} \mathrm{I}$ release rate and the peripheral deiodination rate. In fact the model solution did not require a significant effect of $\mathrm{Li}^{+}$on extrathyroidal iodine metabolism in three of the eight cases.

It seems probable that methimazole does not have a marked effect on either parameter change, since the mean inhibition of release was $52 \%$ and $60 \%$, and of $\mathrm{T}_{3}+\mathrm{T}_{4}$ disappearance was $59 \%$ and $62 \%$ for untreated and methimazole-treated patients, respectively. However, it is not yet possible to say this with certainty. Whether or not the $\mathrm{Li}^{+}$effect on the two parameters is linked (as is suggested by the poor response in both patients $\mathrm{A}$. T. and $H$. B.) requires further study.

The return toward pretreatment rates of these kinetic parameters upon cessation of $\mathrm{Li}^{+}$therapy is also listed in Table II. These values are rough indications, since the mechanism to explain inconsistencies in that region of the data has not yet been worked out. Again there is a wide spectrum of response. $\mathrm{Br}$. J. showed little recovery in either parameter, whereas A. T. and G. F.-2 attained values exceeding the pretreatment rates. It appeared that ${ }^{131}$ I release from the thyroid returned toward normal rates more often than did the thyroxine deiodination rate, but more data are needed before this can be stated with any assurance.

Effect on serum ${ }^{18} I$-hormone levels. The effect of lithium given with and without methimazole on the serum $\mathrm{T}_{4} \mathrm{I}$ is summarized in Table III. In the unblocked patients there was a $25-32 \%$ decrease in $\mathrm{T}_{4} \mathrm{I}$ within 4-5 days, after which there was essentially no further fall, even though the $\mathrm{PB}-{ }^{181} \mathrm{I}$ continued to decline. When lithium was discontinued, there was a rapid (within 4 days) return of the serum $T_{4} I$ to pretreatment levels in three of the four patients. The exception was Br. J. (Fig. $3 C$ ) in whom this return took about 2 wk.

Methimazole-treated patients had a more striking fall (23-59\% in $4-5$ days) of serum hormone levels, three of four reaching a normal serum $\mathrm{T}_{4} \mathrm{I}$ 4-5 days after the start of lithium (the exception, G. V., fell to the upper limit of normal at 10-11 days, despite her failure to respond to 2 months of treatment with high doses of methimazole). In contrast to the unblocked patients, hormone levels continued to fall with continued lithium administration. In addition, the rapid postlithium recovery of serum $T_{4} I$

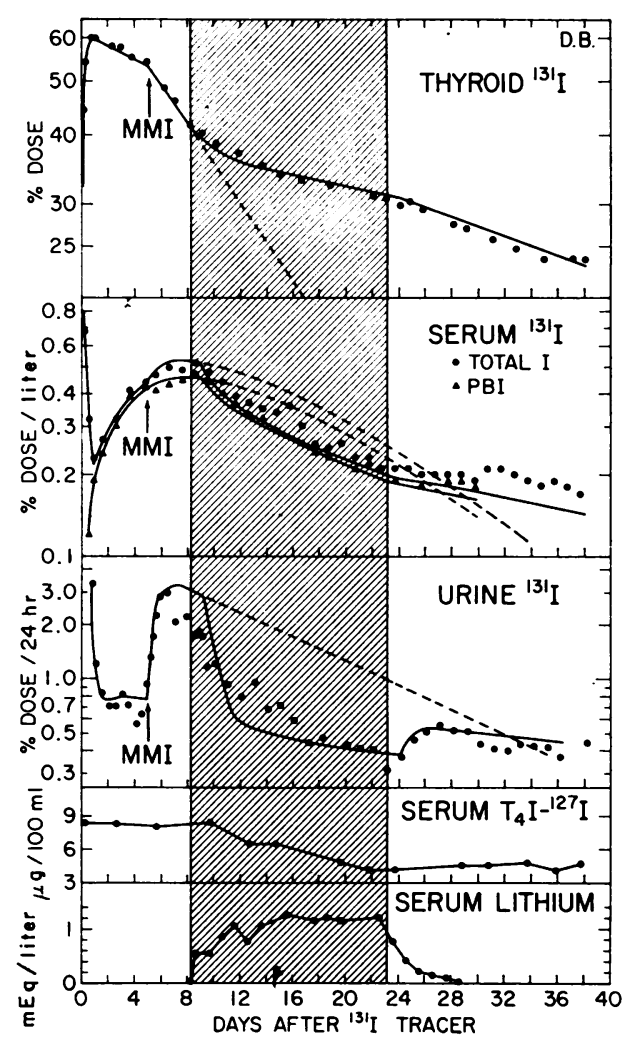

FIgURE $5{ }^{131} \mathrm{I}$ kinetics, serum $\mathrm{T}_{4} \mathrm{I}$, and serum $\mathrm{Li}^{+}$for patient D. B. At time zero $\mathrm{Na}^{131} \mathrm{I}$ was given intravenously. The shaded area is the period of lithium administration and arrows mark the start of methimazole treatment at $30 \mathrm{mg}$ each $6 \mathrm{hr}$. Solid circles and triangles are data points; solid and dashed lines have the same meaning as in Fig. 2.

levels did not occur (Figs. 4 and 5), hormone levels rising only slightly.

Serum $T_{3}$ levels were measured before and after lithium administration in five patients, and appeared to fall somewhat more than the $T_{4}$ levels (Table III). Because of more rapid disappearance rates the $T_{3}$ levels might be expected to fall more rapidly. Studies of early $\mathrm{T}_{\mathbf{s}}$ changes are now in progress.

Clinical changes. The clinical response to lithium correlated in general with the changes of serum $T_{4} I$ levels (Table III). Thus the four patients treated with lithium alone and G. V., of the lithium-methimazole group (only two of whom, Br. J. and G. F.-1, were very symptomatic), had only small changes toward normal. In Br. J., who had the greatest $T_{4} I$ response of that group, a fall in resting pulse $(100-86)$ and BMR $(+31-+19)$ was demonstrated. The greater fall in serum hormone levels in three of the four patients treated with both lithium and methimazole corresponded with a more impressive clinical response, when this could be evaluated. D. B., who was quite symptomatic, became wholly free of symp- 
TABLE III

Serum Thyroxine Iodine and Triiodothyronine Changes after Lithium Therapy

\begin{tabular}{|c|c|c|c|c|c|c|c|}
\hline \multirow[b]{3}{*}{ Patient } & \multirow{3}{*}{$\begin{array}{c}\text { Day's on } \\
\text { methimazole } \\
\text { before } \mathrm{Li}^{+}\end{array}$} & \multirow{3}{*}{$\begin{array}{c}\text { Pre-Li } \mathrm{T}_{4} \mathrm{I}^{*} \\
\text { (mean of several) }\end{array}$} & \multicolumn{3}{|c|}{$\mathrm{T}_{4} \mathrm{I}$} & \multirow{2}{*}{\multicolumn{2}{|c|}{$\mathrm{T}_{3 \ddagger}$}} \\
\hline & & & \multicolumn{3}{|c|}{ Days on $\mathrm{Li}^{+}$} & & \\
\hline & & & $4-5$ & $6-8$ & $10-11$ & Pre-Li $i^{+}$ & $\begin{array}{c}10-14 \mathrm{day}^{10} \\
\text { on } \mathrm{Li}^{+}\end{array}$ \\
\hline & & $\mu \mathrm{g} / 100 \mathrm{ml}$ & $\mu g / 100 \mathrm{ml}$ & $\mu \mathrm{g} / 100 \mathrm{ml}$ & $\mu \mathrm{g} / 100 \mathrm{ml}$ & $n g / m l$ & $n g / m l$ \\
\hline Ba. J. & - & 5.5 & $4.1(25) \S$ & $3.8(31)$ & $4.7(15)$ & 3.1 & $1.9(39)$ \\
\hline Br. J. & - & 13.5 & $9.2(32)$ & 9.1 & $8.0(41)$ & 5.0 & $2.4(52)$ \\
\hline G. F.-1 & - & 15.4 & $10.4(32)$ & $11.4(26)$ & $10.2(34)$ & 7.3 & $3.6(51)$ \\
\hline A. T. & -- & 13.2 & .. - & $9.9(25)$ & $9.3(30)$ & 5.0 & $3.0(40)$ \\
\hline G. I. & 7.6 & 9.2 & - & 7.8 (15) & $6.6(28)$ & 3.1 & 2.5 (19) \\
\hline D. B. & 3.3 & 8.4 & $6.5(23)$ & - & $4.7(44)$ & & - \\
\hline H. B. & 5.3 & 10.0 & $4.8(52)$ & $4.6(54)$ & $\ldots$ & $\ldots$ & - \\
\hline G. F.-2 & 3.1 & 13.8 & $5.7(59)$ & $4.6(67)$ & $3.9(72)$ & - & - \\
\hline
\end{tabular}

* Normal 3.1-6.7 $\mu \mathrm{g} / 100 \mathrm{ml}$.

$\ddagger$ Normal $0.6-1.6 \mathrm{ng} / \mathrm{ml}$.

$\S$ The values in parentheses represent the per cent fall from prelithium levels during lithium therapy.

toms and also had a significant fall in pulse $(74-57)$ and BMR (49-24). H. B. and G. F.-2 also became free of thyrotoxic symptoms, but evaluation was hindered in the former by an upper respiratory infection (pulse and BMR did not fall) and in the latter by the use of propranolol.

In no patient was a change in thyroid gland size noted during the study. Cholesterol levels did not change remarkably in any of the patients. Measurement of free $\mathrm{T}_{4}$ confirmed changes noted in total thyroxine-iodine values. Thyroxine-binding globulin, antithyroglobulin antibodies, and other laboratory determinations did not change significantly during lithium treatment.

The possibility that lithium produced a calming effect on hyperthyroid patients apart from its antithyroid action was considered, but we were unable to detect such a phenomenon. As part of our attempt to evaluate mental changes the study was double blind for both the patient and the psychiatric staff. Although mild depression was observed in several patients, it was associated with the mild anorexia and nausea that occurred at least transiently in most cases, and could not be interpreted as an independent effect. No evidence of lithium toxicity other than gastrointestinal disturbances was observed; in no case were these symptoms severe enough to require discontinuation of the drug, although in G. F.-1 the dose was reduced because of nausea and vomiting.

\section{DISCUSSION}

The present data show that low serum concentrations of lithium ion $(0.5-1.0 \mathrm{mEq} /$ liter $)$ lead rapidly to a $30-85 \%$ decrease in the secretion of both iodide and hormonal iodine from the toxic human thyroid gland, reflected simultaneously in an increased thyroid ${ }^{131} \mathrm{I}$ half-life, decreased urinary ${ }^{131} \mathrm{I}$ excretion, and declining serum ${ }^{131} \mathrm{I}$ and serum thyroxine iodine. The decreased secretion rate follows rapidly the attainment of serum lithium levels of 0.5 $\mathrm{mEq} /$ liter. The effect of lithium was unaltered when iodination was blocked with methimazole. Our data were compatible with a model that assumed coordinate inhibition by lithium of hormonal and nonhormonal iodine release. Such inhibition suggests decreased thyroglobulin hydrolysis, which would reduce secretion of all thyroglobulin components equally. Recent studies in laboratory animals (16, 17) showing that low doses of lithium given in vivo inhibit in vitro colloid droplet formation in response to TSH or dibutyryl cyclic-AMP, strongly support this interpretation.

An unexpected finding, and one that differed from our rat data (5) and from studies in one thyrotoxic ${ }^{2}$ and several euthyroid ${ }^{3}$ patients, was that adjustment of a single kinetic parameter, that describing thyroid iodine secretion, was sufficient to account for the changes in the kinetic curves in only three of the eight patients (e.g., Fig. 2 and Table II). In the others a second effect of $\mathrm{Li}^{+}$ had to be introduced, i.e., one on $\mathrm{T}_{4}$ deiodination. These results emerged entirely from the rigorous modeling and data fitting process and direct measurements of a $\mathrm{Li}^{+}$effect on this parameter were not carried out in this study. Ohlin and Söderberg (18) have reported, without accompanying data, a significant decrease in $T_{4}$ disappearance rate in the rat, and recent investigations by Carlson ${ }^{3}$ in thyrotoxic patients and by Burrow ${ }^{*}$ in both normal and hyperthyroid patients have demonstrated changes in

${ }^{8}$ Dr. H. Carlson, Bethesda, Md. In preparation.

${ }^{4}$ Dr. G. N. Burrow, New Haven, Conn. Personal communication. We should like to thank Dr. Burrow of Yale University School of Medicine for making these values available to us before publication. 
$\mathrm{T}$ 4 disappearance rates following $\mathrm{Li}^{+}$treatment that are entirely in agreement with those presented in Table II.

The decrease in hormone degradation that accompanies the decreased hormone secretion induced by $\mathrm{Li}^{+}$ tends to diminish the fall in serum hormone levels. In some patients (e.g., G. F.-1, Br. J.) the changes in the two parameters would appear to cancel one another. The fact that the serum $T_{4}$ falls in these patients is consistent with our assumption that fecal $T_{4}$ losses are unaffected by lithium, with only losses by deiodination pathways being inhibited. Studies to measure directly the effects of lithium on fecal $\mathrm{T}$, losses are currently in progress.

The model does not at present include a pathway for conversion of $\mathrm{T}_{4-}{ }^{131} \mathrm{I}$ to $\mathrm{T}_{3-}{ }^{181} \mathrm{I}$. With the extent of $\mathrm{T}_{4}$ to $T_{3}$ conversion a matter of controversy at present, inclusion of the pathway would have necessitated selection of wholly arbitrary rate constants and would not have affected our findings of decreased thyroid iodine release and decreased $T_{4}$ deiodination. We plan direct exploration of the $T_{4}$ to $T_{3}$ subsystem in the future, especially with regard to the possibility that lithium might inhibit this conversion.

The present model does not require a lithium effect on iodide uptake. This is in agreement with some studies (9) but contrasts with others in which uptake was decreased $(19,20)$ or increased $(3-5)$. Increased iodide uptake might accompany lithium-induced goiter caused by low circulating $\mathrm{T}_{4}$ and $\mathrm{T}_{3}$ with elevated $\mathrm{TSH}(3,5,9$, $21,22)$. However, none of the present group of thyrotoxic patients became hypothyroid.

The rigorous testing of the model raised several points that require further investigation and analysis. In addition to the effect on hormone disappearance there also seems to be a delayed effect in the action of $\mathrm{Li}^{+}$. This means that instead of plasma $\mathrm{Li}^{+}$some other $\mathrm{Li}^{+}$compartment is probably the important variable to consider. In neglecting these factors the model solution still contains some systematic deviations. It may even be necessary to introduce some time-dependent effects. Until this is investigated in detail and resolved, conclusions about other sites of action of lithium cannot be made with confidence. Hence, the above statements regarding fecal loss and jodide uptake contain an element of uncertainty.

A decreased iodine release rate accompanied by unchanged iodine uptake implies that in unblocked glands, iodine might be expected to accumulate, and such an accumulation has been found in lithium-treated rats (5). The thyroid iodine pools of the lithium-treated patients who did not receive methimazole have been calculated to have increased. This would tend to minimize the fall in serum $T_{4}$ in these patients, as was observed (Figs. 2 and 3 and Table III), and may partly explain the rapid rise of hormone levels when lithium was stopped.
Patients treated with methimazole could not accumulate iodine. This may explain the continued fall of serum and the absence of a substantial postlithium rise in $T_{4} I$ levels.

Except for lithium, iodide is the only agent in clinical use that affects iodine release from the thyroid gland. Iodide decreases ${ }^{131}$ I release from previously labeled thyroid glands in Graves' disease in the presence (23-26) or absence $(23,27,28)$ of methimazole blockade of uptake. It also inhibits TSH-stimulated release of iodine in experimental animals (29) and normal patients $(25,26)$. Wartofsky, Ransil, and Ingbar have recently studied the inhibition of thyroxine release by iodine (23). They found in eight patients that the thyroxine release rate was inhibited an average of $72.8 \%$ (range $61.2-91.5 \%$ ), a somewhat greater inhibition than we have demonstrated for lithium. In a striking parallel to the $\mathrm{Li}^{+}$effect, serum thyroxine levels fell only $26-48 \%$ and tended to level off in 3.5-6.5 days, whether or not methimazole was used with the iodine.

A further similarity between iodine and lithium is the difficulty in controlling thyrotoxicosis for long periods with either agent. In a recent study, Harden, Koutras, Alexander, and Wayne (30) found that patients with good clinical and $T_{4}$ responses to iodide treatment at the end of $2 \mathrm{wk}$ had relapsed by the end of $4 \mathrm{wk}$ despite continued therapy, their $T_{4}$ values returning to pretreatment levels. Since iodine accumulates in thyrotoxic glands treated with Lugol's solution (31), we suggest that in patients treated either with iodide $(23,30)$ or lithium alone, increased glandular hormone content permits total hormone release to rise despite a decreased fractional rate of secretion. This eventually leads to escape from control. Hence the chief use for either agent alone is for short-term, rapid suppression of thyroid secretion. The addition of methimazole or another thiocarbamide drug is necessary to prevent escape from such suppression with prolonged use. Given the uncertainty regarding complete prevention of an iodine leak through methimazole block and the role of iodine as thyroid hormone substrate, lithium appears to be the preferred agent when a rapid inhibition of hormone secretion is required. These considerations must be weighed against the possible toxic effects of lithium and the possibility that the inhibition of $T_{4}$ disappearance by lithium may impair its effectiveness in some instances.

\section{ACKNOWLEDGMENTS}

We thank Doctors George Henry and Dennis Smith of the National Institute of Mental Health for conducting extensive psychiatric evaluations of our patients.

\section{REFERENCES}

1. Temple, R., M. Berman, and J. Wolff. 1971. Reduction of thyroid hormone release by lithium in thyrotoxicosis. J. Clin. Invest. 50: 91a. (Abstr.) 
2. Cade, J. F. J. 1949. Lithium salts in the treatment of psychotic excitement. Med. J. Aust. 2: 349.

3. Schou, M., A. Amdisen, S. E. Jensen, and T. Olsen. 1968. Occurrence of goitre during lithium treatment. Br. Mcd. J. $3: 710$.

4. Sedvall, G. C., B. Jönsson, and U. Pettersson. 1969. Evidence of an altered thyroid function in man during treatment with lithium carbonate. Acta Psychiatr. Scand. Suppl. $207: 59$.

5. Berens, S. C., R. S. Bernstein, J. Robbins, and J. Wolff. 1970. Antithyroid effects of lithium. J. Clin. Invest. $49: 1357$.

6. Danowski, T. S., E. B. Man, and A. W. Winkler. 1946. Additive effects of iodine and thiourea in the treatment of hyperthyroidism. J. Clin. Invest. 25: 597.

7. Ingbar, S. H., and K. A. Woeber. 1968. The thyroid gland. In Textbook of Endocrinology. R. H. Williams, editor. 4th edition. W. B. Saunders Company, Philadelphia. 212.

8. Winkler, A. W., E. B. Man, and T. S. Danowski. 1947. Minimum dosage of thiourea, given together with iodine medication, necessary for the production and maintenance of a remission in hyperthyroidism. J. Clin. Invest. 26: 446 .

9. Burrow, G. N., W. R. Burke, J. M. Himmelhoch, R. P. Spencer, and J. M. Hershman. 1971. Effect of lithium on thyroid function. J. Clin. Endocrinol. Metab. 32: 647.

10. Kessler, G., and V. J. Pileggi. 1970. A semiautomated nonincinerative technique for determining serum thyroxine. Clin. Chem. 16: 382.

11. Lee, N. D., and V. J. Pileggi. 1971. Measurement of free thyroxine in serum. Clin. Chem. 17: 166.

12. Berman, M., E. Hoff, M. Barandes, D. V. Becker, M. Sonenberg, R. Benua, and D. A. Koutras. 1968. Iodine kinetics in man-a model. J. Clin. Endocrinol. Metab. 28: 1 .

13. Berman, M. 1972. Iodine kinetics. In Methods in Investigative and Diagnostic Endocrinology. J. E. Rall and I. J. Kopin, editors. North Holland Publishing Company, Amsterdam, Netherlands. $1: 171$.

14. Koutras, D. A., M. Berman, J. Sfontouris, G. A. Rigopoulos, A. S. Koukoulommati, and B. Malamos. 1970. Endemic goiter in Greece: thyroid hormone kinetics. J. Clin. Endocrinol. Metab. 30: 479

15. Berman, M., and M. F. Weiss. 1967. Users' Manual for SAAM. NIH PHS Publication 1703.

16. Williams, J. A., S. C. Berens, and J. Wolff. 1971. Thyroid secretion in vitro: Inhibition of TSH and dibutyryl cyclic-AMP stimulated ${ }^{131} \mathrm{I}$ release by $\mathrm{Li}^{+}$. Endocrinology. $88: 1385$.

17. Berens, S. C., J. A. Williams, and J. Wolff. 1971. Dis- sociation of thyrotropin-stimulated hormone secretion and glucose oxidation in thyroid glands by lithium and colchicine. Biochim. Biophys. Acta. 252: 314.

18. Ohlin, G., and U. Söderberg. 1970. Inhibition of peripheral utilization of thyroid hormones induced by lithium. Acta Physiol. Scand. 79: 24a. (Abstr.)

19. Cooper, T. B., B. M. Wagner, and N. S. Kline. 1970. Contribution to the mode of action of lithium on iodine metabolism. Biol. Psychiatr. 2: 273.

20. Hullin, R. P., and A. W. Johnson. 1970. Effect of lithium salts on uptake of ${ }^{125} \mathrm{I}$ by fat thyroid gland. Life Sci. 9: 9.

21. Cooper, T. B., and G. M. Simpson. 1969. Preliminary report of a longitudinal study on the effects of lithium on iodine metabolism. Curr. Ther. Res. Clin. Exp. 11: 603

22. Sedvall, G., B. Jönsson, U. Pettersson, and K. Levin. 1968. Effects of lithium salts on plasma protein bound iodine and uptake of $\mathrm{I}^{131}$ thyroid gland of man and rat. Life Sci. $7: 1257$

23. Wartofsky, L., B. J. Ransil, and S. H. Ingbar. 1970. Inhibition by iodine of the release of thyroxine from the thyroid glands of patients with thyrotoxicosis. $J$. Clin. Iniest. 49: 78.

24. Goldsmith, R. E., and M. L. Eisele. 1956. The effect of iodide on the release of thyroid hormone in hyperthyroidism. J. Clin. Endocrinol. Metab. 16: 130.

25. Greer, M. A., and L. J. DeGroot. 1956. The effect of stable iodide on thyroid secretion in man. Metab. Clin. Exp. 5: 682 .

26. Solomon, D. H. 1956. Factors affecting the fractional rate of release of radioiodine from the thyroid gland in man. Metab. Clin. Exp. 5: 667.

27. Ansell, G., and H. Miller. 1952. Influence of iodine on the release of thyroid hormone in thyrotoxicosis. Lancet. 2: 5 .

28. Buhler, U. K., and L. J. DeGroot. 1969. Effect of stable iodine on thyroid iodine release. J. Clin. Endocrinol. Metab. 29: 1546.

29. Ochi, Y., and L. J. DeGroot. 1969. TSH- or LATSstimulated thyroid hormone release is inhibited by iodide. Endocrinology. 84: 1305.

30. Harden, R. McG., D. A. Koutras, W. D. Alexander, and E. J. Wayne. 1964. Quantitative studies of iodine metabolism in iodide-treated thyrotoxicosis. Clin. Sci. 27: 399 .

31. Gutman, A. B., E. M. Benedict, B. Baxter, and W. W. Palmer. 1932. The effect of administration of iodine on the total iodine, inorganic iodine, and thyroxine content of the pathological thyroid gland. J. Biol. Chem. 97: 303 . 